\section{Interacción entre meropenem y ácido valproico: A propósito de dos casos pediátricos}

\author{
Claudio González y Rodolfo Villena
}

\author{
Pharmacological interaction between meropenem and \\ valproic acid: a report of two cases
}

The pharmacological interaction between meropenem and valproic acid is potentially serious, especially in critically ill patients, resulting in low plasmatic levels of the anticonvulsant. However, to our knowledge, this interaction between meropenem and reduced valproic acid plasma levels has not been reported in the pediatric chilean population. We present two clinical cases of chilean children, thus reporting that this interaction is present in our population, with an aim at educating physicians about the possibility of such interaction.

Key words: Valproic acid, valproate, meropenem, interaction.

Palabras clave: Ácido valproico, valproato, meropenem, interacción.

\section{Introducción}

L as interacciones farmacológicas son un tema de creciente conocimiento e importancia en la práctica médica habitual, incluyendo una amplia variedad de medicamentos, lo que debe alertar a los médicos clínicos respecto de las potenciales repercusiones de éstas sobre sus pacientes. Esto cobra especial relevancia en aquellos críticamente enfermos, donde todos los desbalances pueden complicar la evolución y empeorar el pronóstico. Por este motivo la monitorización farmacoterapéutica ayuda a identificar y resolver estos problemas, orientando hacia prácticas más eficaces y seguras.

Meropenem es un antimicrobiano carbapenémico de amplio espectro utilizado en adultos y niños con infecciones graves o por microorganismos multi-resistentes ${ }^{1}$. Se metaboliza en una pequeña proporción, sin participación de enzimas hepáticas, eliminándose por la orina ${ }^{2}$. El ácido valproico se utiliza frecuentemente en pacientes pediátricos con epilepsia y status epiléptico, tanto en su forma oral como intravenosa, siendo metabolizado a nivel hepático, principalmente por glucuronidación sobre su grupo carboxilo $^{3}$. Este metabolito y otros derivados de la metabolización por el citocromo P450 son eliminados por la bilis, experimentando un proceso de recirculación enterohepática ${ }^{3}$. Por estos motivos, tiene la capacidad de alterar la farmacocinética de varios medicamentos, o ser afectado por otros, debiendo monitorizarse para optimizar su eficacia clínica y evitar toxicidad debido a que presenta un estrecho margen terapéutico en sangre (50-125 $\mu \mathrm{g} / \mathrm{ml})^{4}$. En la literatura científica encontramos varias comunicaciones de interacciones en que meropenem reduce las concentraciones de ácido valproico ${ }^{5-8}$, en uno a siete días desde el inicio de la co-administración. Su recuperación, tras la suspensión del carbapenémico, puede extenderse desde tres días hasta dos semanas. Los mecanismos de esta interacción han sido estudiados por varios investigadores los cuales han postulado alteraciones en

\footnotetext{
Hospital de niños Dr. Exequiel González Cortés, Santiago, Chile.

Unidad de paciente crítico (CG, RV).

Conflictos de interés: los autores declaran no tener conflictos de interés.

Financiamiento: Sin financiamiento.
}

Correspondencia a:

Claudio González.

claudio.gonzalezm@redsalud.gov.cl los procesos de eliminación del anticonvulsivante ${ }^{9}$. Uno de los mecanismos que podría explicar esta interacción es la inhibición de la enzima acil-péptido hidrolasa (APEH), por parte de los carbapenémicos, una serina proteasa que se encarga de hidrolizar el glucurónido del ácido valproico y devolverlo a la circulación sistémica ${ }^{10,11}$. La inhibición de la APEH llevaría a la reducción en los niveles sanguíneos de ácido valproico. Otros mecanismos posibles serían la disminución de la absorción gastrointestinal de ácido valproico, aumento de la glucuronización del antiepiléptico o aumento de la retención de ácido valproico en eritrocitos ${ }^{12}$. Sin embargo, el mecanismo íntimo aún no se conoce con exactitud y podría tratarse de una combinación de varios de ellos. Las recomendaciones internacionales varían desde evitar la co-administración ${ }^{13}$ a, en caso de no existir una antibioterapia alternativa, monitorizar los niveles plasmáticos de ácido valproico y considerar su uso en dosis mayores ${ }^{14}$.

De nuestro conocimiento no hay publicaciones en pacientes pediátricos chilenos con esta interacción. La comunicación de estos dos casos tiene como objetivo demostrar que puede presentarse en nuestros pacientes, por lo que debemos estar atentos sobre la posibilidad de este evento.

\section{Materiales y Métodos}

Revisión de las fichas clínicas de dos pacientes hospitalizados en la unidad de paciente crítico (UPC) del Hospital de Niños Dr. Exequiel González Cortés, en tratamiento conjunto con meropenem y ácido valproico entre enero de 2010 y marzo de 2011. Los niveles plasmáticos de ácido valproico se determinaron con técnica inmunoenzimática homogénea (Covas, Roche diagnostics ${ }^{\circledR}$ ). Ambos pacientes utilizaron la misma formulación nacional de ácido valproico en gotas y meropenem.

\section{Caso 1}

Paciente de sexo femenino de un año de edad y $10 \mathrm{~kg}$ de peso corporal, con antecedentes de tetraparesia espástica y epilepsia en monoterapia con fenobarbital oral. Ingresó a UPC por una hemorragia intraventricular, por lo que se realizó una derivación ventricular externa. Evolucionó con una encefalopatía por virus influenza A H1N1, que requirió asociación de fenobarbital $7 \mathrm{mg} / \mathrm{kg} /$ día, fenitoína $5 \mathrm{mg} / \mathrm{kg} /$ día y lorazepam, todos intravenosos, sin lograr yugular las crisis, por lo que se decidió agregar ácido valproico, por sonda nasoyeyunal, a $20 \mathrm{mg} / \mathrm{kg} / \mathrm{día}$, suspendiéndose la fenitoína. A los tres días de su inicio continuó con convulsiones, por lo que se agregó levetiracetam y se tomó el primer nivel plasmático de ácido valproico, siendo de $23,9 \mathrm{mcg} / \mathrm{ml}$, por lo que se aumentó la dosis hasta $50 \mathrm{mg} / \mathrm{kg} / \mathrm{día}$, con lo que se logró un nivel de $37,6 \mathrm{mcg} / \mathrm{ml}$. Al día siguiente se diagnosticó una ventriculitis por Enterobacter cloacae solo sensible a meropenem, por lo que se inició su administración a dosis de $120 \mathrm{mg} / \mathrm{kg} /$ día, lográndose esterilización del LCR a las 48 hrs. Sucesivos niveles plasmáticos de ácido valproico los días 5 y 6 de terapia carbapenémica, demostraron valores menores a $0,19 \mu \mathrm{g} / \mathrm{ml}$, manteniéndose en $3 \mu \mathrm{g} / \mathrm{ml}$ al día 18 . Completó 21 días de meropenem con buena respuesta y sin desarrollar nuevas convulsiones. La recuperación de los niveles plasmáticos de ácido valproico, después de terminada la terapia carbapenémica, fue lenta con valores de $3,4 \mu \mathrm{g} / \mathrm{ml}$ a los 10 días; $11,8 \mu \mathrm{g} / \mathrm{ml}$ a los 28 días; $25,6 \mu \mathrm{g} / \mathrm{ml}$ a $\operatorname{los} 45$ días, recuperándose hasta $95,9 \mu \mathrm{g} / \mathrm{ml}$ a los 48 días, sin realizarse cambios en la dosis $(50 \mathrm{mg} / \mathrm{kg} /$ día). No presentó alteraciones de enzimas hepáticas ni albúmina durante su hospitalización. Sesenta y seis días después de terminada la terapia conjunta se dio de alta con fenobarbital, levetiracetam y ácido valproico oral.

\section{Caso 2}

Paciente de sexo femenino, de 5 años de edad y $23 \mathrm{~kg}$ de peso corporal, con antecedentes de parálisis cerebral por asfixia neonatal y epilepsia, en 
tratamiento prolongado con ácido valproico oral, $32 \mathrm{mg} / \mathrm{kg} /$ día administrados por sonda nasogástrica (SNG). Ingresó a la UPC por una neumonía por adenovirus, asociada a insuficiencia respiratoria grave y shock sépticohipovolémico refractario a catecolaminas, recibiendo hidrocortisona en dosis de estrés y asociándose terapia antimicrobiana con cefotaxima, clindamicina y amikacina iv. El octavo día de hospitalización se tomó un nivel plasmático de ácido valproico, el que resultó en $90,1 \mu \mathrm{g} / \mathrm{ml}$. El décimo día de hospitalización presentó un deterioro hemodinámico y respiratorio, con cultivo de aspirado traqueal para Pseudomonas aeruginosa, por lo que se cambió esquema antimicrobiano a vancomicina y meropenem $(120 \mathrm{mg} / \mathrm{kg} / \mathrm{día})$, manteniendo amikacina. Tras cinco días de tratamiento con meropenem se monitorizó el ácido valproico, encontrándose un valor plasmático $<3 \mu \mathrm{g} /$ $\mathrm{ml}$. Por estrategia de de-escalamiento se suspendió el carbapenémico. El ácido valproico se aumentó a $45 \mathrm{mg} / \mathrm{kg} /$ día, controlándose un nuevo nivel plasmático siete días después de la suspensión de meropenem, cuyo resultado fue de $55 \mu \mathrm{g} / \mathrm{ml}$. Catorce días después de la suspensión de meropenem el paciente presentó nuevo deterioro hemodinámico debido a una sepsis por Enterobacter cloacae identificada en hemocultivos y secreción traqueal, reiniciándose nuevamente el carbapenémico a igual dosis que la vez anterior, provocando una nueva caída de los niveles plasmáticos de ácido valproico a $<3 \mu \mathrm{g} / \mathrm{ml}$, a los dos días de reiniciado. Se mantuvo con igual dosis de valproato. Transcurridos 20 días de terapia carbapenémica falleció por falla hipoxémica refractaria.

\section{Discusión}

Meropenem es un antimicrobiano carbapenémico de amplio espectro utilizado en infecciones graves en pediatría. Por mucho tiempo se le consideró libre de interacciones medicamentosas, hasta la primera comunicación con ácido valproico realizado por De Turck y cols., el año $1998^{7}$.

Los casos presentados buscan llamar la atención acerca de la posibilidad de esta interacción en los pacientes pediátricos, sobre todo en aquellos hospitalizados en UPC por condiciones neurológicas, donde el ácido valproico es con frecuencia parte de sus terapias. Existen publicaciones internacionales de esta interacción en pacientes pediátricos ${ }^{8,15}$ pero no encontramos comunicaciones de casos en adultos o niños chilenos. Es importante destacar que al igual que meropenem, los otros carbapenémicos como imipenem, doripenem y ertapenem pueden producir el mismo proble$\mathrm{ma}^{12}$. La adición de meropenem a una terapia estable con ácido valproico, reduce las concentraciones del antiepiléptico de forma rápida en $\sim 70 \%{ }^{13,14}$. En nuestros pacientes se observaron reducciones similares en el caso 1, mientras que en el caso 2 la reducción fue más dramática llegando hasta el límite de detección del examen en las dos terapias con meropenem. En el caso 2, el aumento de la dosis de ácido valproico no logró aumentar sus niveles plasmáticos mientras estuvo presente el carbapenémico, hallazgo similar a otros casos publicados en la literatura ${ }^{13}$. Se ha descrito un tiempo de recuperación de los niveles en torno a 8 días (hasta 2 semanas) desde la suspensión de meropenem ${ }^{13,14}$, situación que se confirmó en el caso 2; sin embargo, en el caso 1 la recuperación se produjo a los 48 días de suspendida la co-administración. Esta latencia podría explicarse por la predisposición del paciente 1 a niveles sub-terapéuticos de ácido valproico y por la inducción enzimática provocada por el tratamiento concomitante con fenobarbital. El impacto de esta interacción en pacientes que presentan niveles bajos de ácido valproico, ya sea por presencia de inductores enzimáticos u otras causas, debería medirse en un estudio diseñado para tal efecto. Clínicamente esta interacción se traduce en una alta posibilidad de convulsiones; sin embargo, éstas no fueron evidenciadas en los dos casos descritos, lo que podría explicarse por el uso concomitante de sedación con benzodiazepinas en el caso 2, o requerimiento de múltiples asociaciones anticonvulsivantes, como ocurrió en el caso 1. A pesar de su ausencia, es importante destacar que la aparición de convulsiones podría ser una de las primeras manifestaciones clínicas de la interacción y se debe evaluar su posibilidad durante todo el tratamiento asociado.

En ambos casos, existió administración de ácido valproico por sondas enterales, lo que pudo representar un factor de riesgo para obtener niveles bajos debido a la posibilidad de fijación a la sonda o alteraciones locales en la absorción del antiepiléptico, situaciones que pueden existir con este método de administración ${ }^{16}$. Esta posibilidad se descartó en el caso 1 por el retiro temprano de la sonda, mientras que en el caso 2 persistió con la sonda hasta el final del seguimiento. Además, en ambos casos existió una clara relación causal entre la administración de meropenem y ácido valproico, independiente del uso de sonda, lo que también descartaría la influencia de este método de administración.

La ficha técnica del meropenem explicita que la co-administración de ácido valproico y agentes carbapenémicos no es manejable y que, por tanto, debe evitarse ${ }^{17}$. Por la evidencia actual no parece una opción utilizar la forma intravenosa, ya que se ha descrito de igual forma la interacción ${ }^{14,18}$. Si es necesario utilizar ambos medicamentos se debe realizar un seguimiento farmacoterapéutico estrecho y evaluar la opción de agregar un nuevo anticonvulsivante.

A través de la comunicación de estos dos casos queremos invitar a tener presente esta interacción potencialmente grave cada vez que se indique meropenem o cualquier carbapenémico en pacientes con ácido valproico como terapia concomitante.

Agradecimientos: A la Dra. Michele Drago y el equipo de la UPC del Hospital de Niños Dr. Exequiel González Cortés por su colaboración y al QF clínico Jorge Morales V. por su apoyo.

\section{Resumen}

La interacción farmacológica entre meropenem y ácido valproico en pacientes críticos es potencialmente grave, reflejándose en una disminución del fármaco anticonvulsivante mayor a $70 \%$. Se desconocen estrategias efectivas que la reviertan. Esta interacción no ha sido descrita en pacientes chilenos pediátricos. A través de la presentación de dos casos clínicos alertamos que la interacción puede suceder en nuestra población y educamos a los pediatras que indican meropenem sobre la posibilidad de este evento.

\section{Referencias bibliográficas}

1.- Baldwin C M, Lyseng-Williamson K A, Keam S J. Meropenem: a review of its use in the treatment of serious bacterial infections. Drugs 2008; 68 : 803-38.

2. - Burman L A, Nilsson-Ehle I, Hutchison M, Haworth S J, Norrby S R. Pharmacokinetics of meropenem and its metabolite ICI 213,689 in healthy subjects with known renal metabolism of imipenem. J Antimicrob Chemother 1991; 27: 219-24.

3.- Guerrini R. Valproate as a mainstay of therapy for pediatric epilepsy. Paediatr Drugs 2006; 8: 113-29.

4.- Patsalos P N, Berry D J, Bourgeois B F, Cloyd J C, Glauser T A, Johannessen SI, et al. Antiepileptic drugs-best practice guidelines for therapeutic drug monitoring: a position paper by the subcommission on therapeutic drug monitoring, ILAE Commission on Therapeutic Strategies. Epilepsia 2008; 49: 1239-76.

5.- Fudio S, Carcas A, Piñana E, Ortega R. Epileptic seizures caused by low valproic acid levels from an interaction with meropenem. J Clin Pharm Ther 2006; 31: 393-6.

6.- Tobin J K, Golightly L K, Kick S D, Jones M A. Valproic acid-carbapenem interaction: report of six cases and a review of the literature. Drug Metabol Drug Interact 2009; 24: 153-82. 